
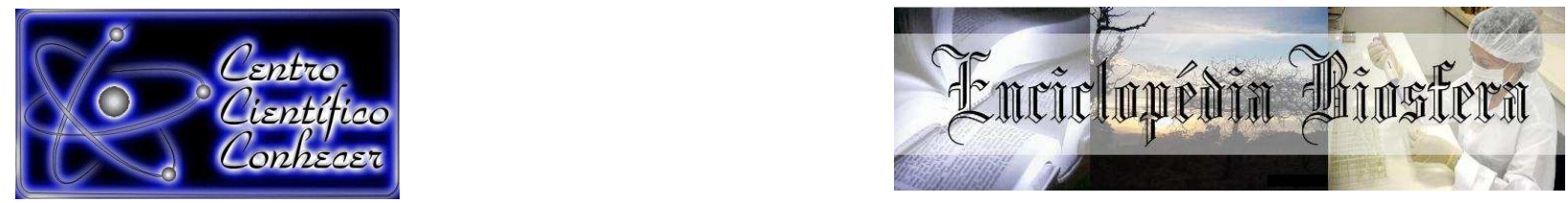

\title{
PERFIL EPIDEMIOLÓGICO DE ACIDENTES OFÍDICOS NO ESTADO DO RIO GRANDE DO SUL NO PERÍODO DE 2007 A 2013
}

Róger Jean Oliveira ${ }^{1}$; Rosane Maria Kirchner ${ }^{2}$; Mônica Elisa Scherer ${ }^{3}$; Ethiane Rozo dos Santos ${ }^{1}$; Luciana Patricia Shumacher Eidelwein ${ }^{4}$.

1 Acadêmicos do curso de Ciências Biológicas da Universidade Federal de Santa Maria (roger20j@hotmail.com) Palmeira das Missões-Brasil

2 Professora doutora do departamento de Biologia e Zootecnia da Universidade Federal de Santa Maria

3 Mestranda em Administração pela Universidade Federal de Santa Catarina 4 Mestranda em educação pela Universidade Federal de Santa Maria

Recebido em: 08/09/2015 - Aprovado em: 14/11/2015 - Publicado em: 01/12/2015 DOI: http://dx.doi.org/10.18677/Enciclopedia_Biosfera_2015_024

\begin{abstract}
RESUMO
Acidentes ocasionados por serpentes são importantes problemas de saúde, principalmente em países tropicais, onde os acidentes ocorrem com certa frequência. Este estudo objetivou analisar os aspectos epidemiológicos dos acidentes ofídicos no Estado do Rio Grande do Sul, Brasil no período de 2007 a 2013. Os dados foram coletados no SINAN - Sistema de Informação de Agravos de Notificação, utilizando a modalidade "Notificações por animais peçonhentos, selecionando a categoria serpentes". Foram notificados neste período 6.714 acidentes, com uma média de 959 casos por ano. Em relação aos indivíduos acidentados, os homens foram mais acometidos, totalizando $74,9 \%$ das notificações. A faixa etária predominante dos acidentes esteve entre 40-60 anos, com percentuais variando entre $32,5 \%$ e $40 \%$. Os meses de outubro a abril corresponderam ao período de maior incidência de notificações totalizando $86,5 \%$ dos casos. Quando identificada a serpente, o gênero Bothrops foi o responsável pela maioria dos incidentes, com percentuais variando entre $83,0 \%$ e $88,5 \%$ das notificações. Com relação ao tempo decorrido entre a picada e o atendimento médico, maior parte dos acidentados foram atendidos em menos de uma hora, com valores oscilando entre $43,8 \%$ e 47,7\%. As taxas de cura foram consideráveis, apresentando percentuais entre $87,2 \%$ e $90,3 \%$. O desenvolvimento deste trabalho permitiu tomar conhecimento sobre a situação epidemiológica dos acidentes ofídicos no Rio Grande do Sul, e desta forma podendo servir como base para trabalhos posteriores, bem como futuras medidas de prevenção de acidentes por parte das unidades de saúde.
\end{abstract}

PALAVRAS-CHAVE: Acidentes ofídicos, Epidemiologia, Serpentes peçonhentas.

\section{EPIDEMIOLOGICAL PROFILE OF SNAKEBITES IN THE STATE OF RIO GRANDE DO SUL FROM 2007 TO 2013}

\begin{abstract}
Accidents caused by snakes are a major health problem, especially in tropical countries, where accidents occur fairly often. This study aimed to analyze the
\end{abstract}


epidemiological aspects of snake bites in the state of Rio Grande do Sul, Brazil from 2007 to 2013. Data were collected in SINAN - System the Information of Diseases Notifiable, using the form "notifications by venomous animals, selecting the category - snakes". It has been reported in these period 6.714 accidents, with an average of 959 cases per year. Regarding the injured individuals, men were most affected, totaling $74,9 \%$ of the notifications. The age distributions of the accidents were between $40-60$ years, with percentages ranging from $32,5 \%$ to $40 \%$. The months from October to April corresponded to the period of highest incidence of notifications totaling $86,5 \%$ of cases. When identified the snake, the genre Bothrops was responsible for most incidents, with percentages ranging between $83,0 \%$ and $88,5 \%$ of notifications. Regarding the time between the bite and the medical care, most of the victims were met in less than 1 hour, with values ranging between $43,8 \%$ and $47,7 \%$. The cure rates were considerable, with percentages between $87,2 \%$ and $90,3 \%$. The development of this work allowed taking knowledge of the epidemiological situation of snakebites in Rio Grande do Sul, and this form can serve as basis for future works, as well as future accident prevention measures by the health units.

KEYWORDS: Epidemiology, Snakebites, Venomous snakes.

\section{INTRODUÇÃO}

Acidentes ocasionados por ofídios peçonhentos representam importante problema de saúde pública, principalmente em regiões tropicais, onde ocorrem com certa frequência, acarretando morbidade e mortalidade (BARRETO et al., 2010; BRITO \& BARBOSA, 2012). Estima-se que ocorram entre 421.000 e 1.841 .000 envenenamentos e de 20.000 a 94.000 mortes decorrentes de picada de serpentes por ano, contudo considerando que o envenenamento acontece em cerca de um em cada três acidentes ofídicos, poderia ocorrer entre 1,2 milhões e 5,5 milhões picadas de serpentes mundialmente por ano (KASTURIRATNE et al., 2008).

A ocorrência dos acidentes ofídicos está associada a alguns fatores, como o clima, no qual os incidentes predominam nos meses mais quentes e chuvosos do ano e também fortemente relacionado a atividade humana em trabalhos agrícolas nas áreas rurais (BRASIL, 2001; MARTINS et al., 2012). Contudo, o ofidismo geralmente visto como um problema rural vem gradativamente se tornando um problema em áreas urbanas, principalmente devido a construção de moradias em locais inapropriados, além do acúmulo de lixo e outros detritos em residências e terrenos baldios (CARDOSO et al., 2009).

Os casos de acidentes envolvendo serpentes, muitas vezes são notificados de maneira incorreta pelas unidades de saúde, considerando que frequentemente a as pessoas utilizam métodos inapropriados, baseados no conhecimento sem caráter científico, além de que, estudos que envolvam a fauna regional de serpentes serem raros (D'AGOSTINI et al., 2011). Entretanto, notificações sobre número de picadas, envenenamentos e óbitos, devido a acidentes ofídicos, são fundamentais para saber a real situação do problema, capacitação do pessoal da saúde para tratar os acometidos pelo agravo, além de planejamento de ações educativas e preventivas relacionadas a esta problemática (KASTURIRATNE et al., 2008; MESCHIAL et al., 2013).

Os incidentes entre homens e serpentes são evidenciados, no Brasil, desde o descobrimento (BARROSO \& WOLFF, 2012). No entanto, os primeiros estudos relacionados ao ofidismo, foram realizados por Vital Brazil no instituto Serum terápico, hoje denominado Instituto Butantan, sendo que, tiveram início no princípio 
do século XX. Este pesquisador introduziu boletins para análise e observação dos acidentes ofídicos quando iniciou a produção de soros (LEMOS et al., 2009). Para os mesmos autores até os anos 80 os estudos de notificação eram centralizados, sendo desenvolvido especialmente em torno da região sudeste.

A partir de 1986, o Ministério da Saúde tornou obrigatória a notificação dos acidentes por animais peçonhentos criando várias medidas, sendo uma a criação do Programa Nacional de Ofidismo, na antiga Secretária de Ações Básicas da Saúde (SNABS/MS). Então, foi possível criar um perfil epidemiológico e clínico da população relacionado ao ofidismo, melhorando assim as condições de tratamento e atendimento dos acidentados, além da permuta de informações epidemiológicas por soro entre as Secretarias Estaduais e o Ministério da Saúde (LEMOS et al., 2009; OLIVEIRA et al., 2011). Segundo BARROSO \& WOLFF (2012, p.79) "o Brasil foi destaque na identificação, classificação das serpentes, determinação do quadro clínico e, principalmente, no desenvolvimento do soro antiofídico".

Atualmente no Brasil, existem aproximadamente 386 espécies de serpentes, sendo estas distribuídas em diversas famílias, e somente duas abrangem as serpentes consideradas peçonhentas, pertencendo as famílias Viperidae e Elapidae (D’AGOSTINI et al., 2011; BÉRNILS \& COSTA, 2014).

Essas famílias Viperidae e Elapidae englobam as espécies que são denominadas peçonhentas, pelo fato de produzirem toxinas em glândulas especializadas, por meio de aparelhos apropriados para inoculação de peçonha, deste modo, acarretando intoxicações potencialmente graves em humanos e animais domésticos. Entretanto, é sabido que diversas espécies consideradas não peçonhentas, como alguns colubrídeos, secretam substâncias químicas por meio de glândulas cefálicas para ajudar na digestão e ingestão de alimentos, que podem ser tóxicas aos humanos (CARDOSO et al., 2009).

A maior parte dos acidentes registrados nos limites geográficos brasileiros é causada por serpentes pertencentes aos gêneros Bothrops, Crotalus, Lachesis e Micrurus e ocorrem em todos os estados do Brasil (OLIVEIRA et al., 2011; BARRETO et al., 2010; MORAES et al., 2010). Espécies pertencentes ao gênero Bothrops, são os maiores responsáveis pelos acidentes ofídicos com cerca de $90 \%$ dos acidentes e letalidade de 0,3\% (BERNARDE, 2012; MARTINS et al., 2012). Todo ano são notificados aproximadamente 20.000 acidentes por serpentes no Brasil (CARDOSO et al., 2009; OLIVEIRA et al., 2011).

As regiões Centro-Oeste e a Norte são as regiões do território brasileiro com maior incidência de acidentes ofídicos por cada 100 mil habitantes. Entretanto, é presumível que a região Nordeste apresente altos índices de acidentes, mesmo levando em conta os elevados percentuais de subnotificações, devido as dificuldades de acesso aos serviços médicos (BRITO \& BARBOSA, 2012).

No estado do Rio grande do Sul, as serpentes estão englobadas em sete famílias, representadas por 88 espécies, e dentre estas, são três os grupos de serpentes responsáveis pelos acidentes de alta gravidade, sendo Bothrops (jararacas, cruzeira, cotiara, outras), Crotalus (cascavel) e Micrurus (coral) (ABEGG \& NETO, 2012). Embora sejam conhecidos os principais gêneros ofídicos responsáveis pelo agravo, poucos estudos relacionados a características que envolvem a problemática foram realizados. Frente ao exposto, esta pesquisa buscou avaliar aspectos epidemiológicos dos casos de acidentes decorrentes de ofídios no Rio Grande do Sul durante o período de 2007 a 2013. 


\section{MATERIAL E MÉTODOS}

Esta pesquisa realizou-se a partir de dados obtidos no SINAN - Sistema de Informação de Agravos de Notificação (BRASIL, 2014), considerando a modalidade Notificações por Animais Peçonhentos, selecionando a categoria Serpentes. As informações são do período de 2007 a 2013 no Estado do Rio Grande Sul. A abordagem é quantitativa e descritiva. As variáveis estudadas envolvem o sexo, idade, evolução do caso, tempo de atendimento dos acidentados e o gênero das serpentes ocasionadoras do agravo, bem como, o mês da ocorrência. A análise dos dados foi realizada com auxilio da estatística descritiva, utilizando o Microsoft Office Excel. Os resultados obtidos são apresentados em figuras e tabela cruzada.

\section{RESULTADOS E DISCUSSÃO}

Durante o período de 2007 a 2013, foram notificados 6.714 acidentes ofídicos, apresentando uma média anual de 959 incidentes ocasionados por serpentes no Rio Grande do Sul. Neste contexto, conforme LEMOS et al. (2009) podem ocorrer subnotificação dos casos de acidentes por animais peçonhentos, por parte dos sistemas responsáveis, considerando fatores como obstáculos de acesso aos serviços de saúde de vários municípios.

Segundo a pesquisa realizada com os dados do SINAN, observou-se que em relação ao sexo dos indivíduos, os homens foram mais acometidos, totalizando $74,9 \%$ dos casos e as mulheres em $25,0 \%$, além de uma pequena parcela menor que $0,1 \%$ onde não foi identificado o sexo. No entanto, esses elevados percentuais com relação ao sexo masculino deve-se provavelmente, a maior atividade do homem fora da residência, como trabalho ou lazer (ROJAS et al., 2007). Esta mesma característica ocorre de forma semelhante em estudos realizados em outras regiões do Brasil (BOCHNER \& STRUCHINER, 2003).

$\mathrm{Na}$ Tabela 1, observa-se que as taxas de cura, nos anos estudados, demonstraram resultados consideráveis, apresentando percentuais variando entre $87,2 \%$ e $90,3 \%$. Estes altos índices de cura provavelmente devem-se a rápida procura por atendimento médico, por parte dos acidentados a fim de tomar o soro específico. Segundo LEMA (2002), em caso de acidentes por serpentes peçonhentas, a utilização do soro-antiofídico em menor tempo possível, além de um tratamento de apoio como limpeza local, hidratação, anti-inflamatórios, entre outros, tornam grandes as chances de cura do indivíduo acometido pelo ofidismo.

TABELA 1: Notificação da Evolução dos casos de acidentes ocasionados por serpentes no Rio Grande do Sul de 2007 a 2013.

\begin{tabular}{lcccccccc}
\hline & & \multicolumn{7}{c}{ Ano } \\
\cline { 2 - 9 } & & 2007 & 2008 & 2009 & 2010 & 2011 & 2012 & 2013 \\
\hline Cura & $\mathrm{N}$ & 958 & 846 & 960 & 887 & 862 & 730 & 686 \\
& $\%$ & 87,9 & 89,5 & 88,3 & 87,2 & 90,3 & 87,2 & 87,6 \\
\hline Óbito & $\mathrm{N}$ & - & - & - & - & 2 & 4 & 3 \\
& $\%$ & - & - & - & - & 0,2 & 0,5 & 0,4 \\
\hline Ign/Branco & $\mathrm{N}$ & 132 & 99 & 127 & 130 & 91 & 103 & 94 \\
& $\%$ & 12,1 & 10,5 & 11,7 & 12,8 & 9,5 & 12,3 & 12,0 \\
\hline
\end{tabular}

Fonte: Elaborada pelos autores com base nos dados do SINAN sujeitos a atualização. 
Quanto às notificações de óbito, houve registros apenas nos anos de 2011, 2012 e 2013, com o maior percentual no ano de 2012, onde apresentou-se no valor de $0,5 \%$. Geralmente os incidentes fatais ocasionados por animais peçonhentos, são acarretados em virtude da falta de cuidados necessários aos acidentados, frequentemente em crianças, idosos e pessoas com sistema imunológico debilitado (BARROSO \& WOLFF, 2012). Também a adoção de práticas não usuais, em caso de acidente com serpentes, podem acarretar agravamento da situação clínica do indivíduo acometido pelo ofidismo (MOURA et al., 2010). Para ABEGG \& NETO (2012), atitudes como torniquete, chupar o veneno, ou passar substâncias sobre o local da picada além de não contribuírem para a melhora clínica do acidentado, esta última, pode ocasionar lesões e inflamações.

Com relação aos eventos ignorados ou em branco, os quais são os casos em que não foi notificado se ocorreu a cura ou a morte do indivíduo acidentado, nestes, nos anos estudados, é possível identificar valores variando entre $9,5 \%$ e $12,8 \%$. A verdadeira incidência mundial de acidentes ofídicos, seu impacto, e particularidades de cada região, permanecem desconhecidos, principalmente em áreas rurais, o que acaba dificultando a real magnitude do problema (KASTURIRATNE et al., 2008).

Considerando o tempo decorrido entre a picada e o atendimento médico (Tabela 2), observou-se que a maioria dos acidentados foram atendidos em menos de uma hora, com percentuais oscilando entre $43,8 \%$ e $47,7 \%$, seguida do atendimento de uma a três horas, representando um percentual que variou de 33,4 a $36,8 \%$, dos casos (Tabela 2). O tempo entre a picada e o atendimento médico é crucial para que se obtenha sucesso no tratamento e para definição da evolução do caso (BRITO \& BARBOSA, 2012).

TABELA 2: Notificação do tempo de atendimento após a picada, dos casos de acidentes ocasionados por serpentes no Rio Grande do Sul de 2007 a 2013.

\begin{tabular}{ccccccccc}
\hline & & \multicolumn{7}{c}{ Ano } \\
\cline { 2 - 8 } & 2007 & 2008 & 2009 & 2010 & 2011 & 2012 & 2013 \\
\hline \multirow{2}{*}{ 0 a 1 h } & $\mathrm{N}$ & 486 & 428 & 476 & 465 & 456 & 398 & 363 \\
& $\%$ & 44,6 & 45,3 & 43,8 & 45,7 & 47,7 & 47,6 & 46,4 \\
\hline \multirow{2}{*}{ 1 a 3 hs } & $\mathrm{N}$ & 381 & 339 & 391 & 367 & 319 & 289 & 288 \\
& $\%$ & 35,0 & 35,9 & 36,0 & 36,1 & 33,4 & 34,5 & 36,8 \\
\hline \multirow{2}{*}{3 a 6 hs } & $\mathrm{N}$ & 84 & 75 & 80 & 66 & 52 & 46 & 58 \\
& $\%$ & 7,7 & 7,9 & 7,4 & 6,5 & 5,4 & 5,5 & 7,4 \\
\hline \multirow{2}{*}{6 a 12hs } & $\mathrm{N}$ & 17 & 20 & 22 & 17 & 14 & 14 & 15 \\
& $\%$ & 1,6 & 2,1 & 2,0 & 1,7 & 1,5 & 1,7 & 1,9 \\
\hline \multirow{2}{*}{12 a 24 hs } & $\mathrm{N}$ & 24 & 13 & 23 & 23 & 21 & 14 & 12 \\
& $\%$ & 2,2 & 1,4 & 2,1 & 2,3 & 2,2 & 1,7 & 1,5 \\
\hline \multirow{2}{*}{ 24 ou +hs } & $\mathrm{N}$ & 13 & 16 & 29 & 26 & 21 & 14 & 6 \\
& $\%$ & 1,2 & 1,7 & 2,7 & 2,6 & 2,2 & 1,7 & 0,8 \\
\hline \multirow{2}{*}{ Ign/Branco } & $\mathrm{N}$ & 85 & 54 & 66 & 53 & 72 & 62 & 41 \\
& $\%$ & 7,8 & 5,7 & 6,1 & 5,2 & 7,5 & 7,4 & 5,2 \\
\hline
\end{tabular}

Fonte: Elaborada pelos autores com base nos dados do SINAN sujeitos a atualização.

Verificou-se (Tabela 3) que nos anos estudados a faixa etária predominante dos acidentes ofídicos esteve entre 40-60 anos, na qual foi evidenciado o maior número de ocorrências em todos os anos da pesquisa, com percentuais variando entre $32,5 \%$ e $40 \%$, cabendo destaque ao ano de 2010 , onde esta faixa etária 
correspondeu a $40 \%$ das notificações. Acidentes com pessoas entre $20-40$ anos de idade foram o segundo mais relatado, apresentando percentuais entre $25,3 \%$ e $34,4 \%$ do total de casos notificados anualmente. Vale mencionar índices consideráveis de casos com 60 anos ou mais, o qual variou entre $12,5 \%$ e $18 \%$. Este fato deve-se, provavelmente ao aumento da expectativa de vida da população alcançada nos últimos anos, e o grande número de idosos que desempenham trabalho na área rural (PINHO et al., 2004). O percentual da faixa etária até 10 anos oscilou entre $4,9 \%$ e 7,1\%. Este fato pode estar relacionado as características de cores chamativas de algumas serpentes, levando crianças a manipular por curiosidade e assim ocasionando acidentes (RODRIGUES, 2006).

TABELA 3: Notificação da faixa etária de ocorrência dos casos de acidentes ocasionados por serpentes no Rio Grande do Sul de 2007 a 2013.

\begin{tabular}{lcccccccc}
\hline & & \multicolumn{7}{c}{ Ano } \\
\cline { 2 - 9 } & 2007 & 2008 & 2009 & 2010 & 2011 & 2012 & 2013 \\
\hline Menos de 10 & $\mathrm{N}$ & 75 & 57 & 72 & 72 & 61 & 41 & 48 \\
& $\%$ & 6,9 & 6,7 & 6,6 & 7,1 & 6,4 & 4,9 & 6,1 \\
\hline $10-20$ & $\mathrm{~N}$ & 147 & 147 & 169 & 117 & 136 & 125 & 89 \\
& $\%$ & 13,5 & 17,4 & 15,5 & 11,5 & 14,2 & 14,9 & 11,4 \\
\hline $20-40$ & $\mathrm{~N}$ & 338 & 291 & 347 & 294 & 250 & 212 & 199 \\
& $\%$ & 31,0 & 34,4 & 31,9 & 28,9 & 26,2 & 25,3 & 25,4 \\
\hline $40-60$ & $\mathrm{~N}$ & 378 & 327 & 353 & 407 & 356 & 328 & 305 \\
& $\%$ & 34,7 & 38,7 & 32,5 & 40,0 & 37,3 & 39,2 & 39,0 \\
\hline 60 ou mais & $\mathrm{N}$ & 151 & 123 & 146 & 127 & 152 & 131 & 142 \\
& $\%$ & 13,9 & 14,6 & 13,4 & 12,5 & 15,9 & 15,7 & 18,1 \\
\hline
\end{tabular}

Fonte: Elaborada pelos autores com base nos dados do SINAN sujeitos a atualização.

Na Figura 1, observa-se a ocorrência mensal de acidentes durante o período de estudo. Verifica-se que estes foram mais frequentes entre os meses de outubro e abril, correspondendo a 5841 dos 6714 casos notificados, ou seja, $87 \%$ dos registros no período de estudo. Estes dados coincidem com informações presentes na literatura, conforme LEMOS et al. (2009), nas regiões Sul e Sudeste, os acidentes ofídicos sobressaem-se nos meses de outubro a abril, o qual é marcado por época quente e chuvosa. O ofidismo está fortemente influenciado pela relação entre clima e pluviosidade, os quais explicam a predominância dos acidentes em determinados períodos do ano (CARDOSO et al., 2009). 


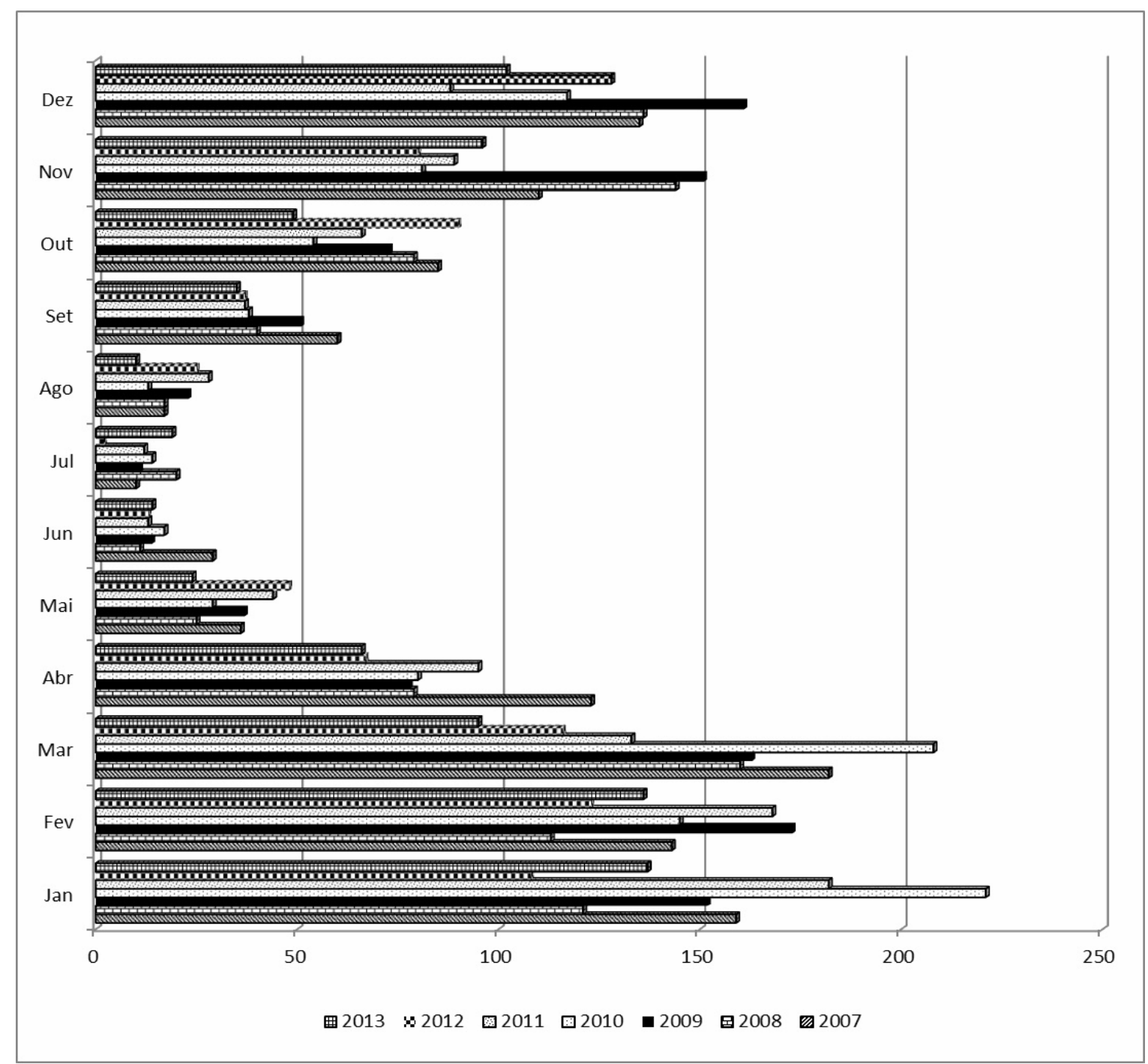

FIGURA 1 - Notificações de acidentes por serpentes segundo mês e ano de ocorrência no Rio Grande do Sul no período de 2007 a 2013.

Fonte: Elaborada pelos autores com base nos dados do SINAN sujeitos a atualização.

O aumento da atividade agrícola nesta época do ano também é um dos fatores relacionados ao acidente ofídico, especialmente com agricultores, os quais estão envolvidos diretamente em tarefas rurais, consequentemente, expondo esses trabalhadores aos ofídios (PINHO et al., 2004; MORAES et al., 2010).

Nos meses de maio a setembro, correspondente aos meses mais frios do ano, houve decréscimo nas ocorrências, sendo registrados nesta época 13\% das notificações. Períodos com baixas temperaturas acarretam queda no metabolismo das serpentes, além de causar diminuição de presas para sua alimentação, tornando estas menos ativas e desta forma sendo menos provável os acidentes em estações frias do ano (CARDOSO et al., 2009; ROJAS et al., 2007).

Quanto ao gênero da serpente responsável pelo agravo (Tabela 4), o gênero Bothrops foi predominante, com percentuais variando entre $83,0 \%$ e $88,5 \%$ dos casos registrados anualmente. Estes altos índices estão relacionados a grande abundância destas nos ecossistemas, sendo encontradas principalmente em matas e ambientes úmidos, além de áreas cultivadas e periferias de grandes cidades, as 
quais acabam atraindo roedores, umas das principais presas destas serpentes (SCATENA, 2013).

TABELA 4: Notificação dos acidentes ofídicos no Rio Grande do Sul segundo o gênero da serpente no período de 2007 a 2013.

\begin{tabular}{c|c|c|c|c|c|c}
\hline Ano & $\begin{array}{c}\text { Ign/Branco } \\
\mathrm{N}(\%)\end{array}$ & $\begin{array}{c}\text { Bothrops } \\
\mathrm{N}(\%)\end{array}$ & $\begin{array}{c}\text { Crotalus } \\
\mathrm{N}(\%)\end{array}$ & $\begin{array}{c}\text { Micrurus } \\
\mathrm{N}(\%)\end{array}$ & $\begin{array}{c}\text { Não } \\
\text { Peçonhenta } \\
\mathrm{N}(\%)\end{array}$ & $\begin{array}{c}\text { Total } \\
\mathrm{N}(\%)\end{array}$ \\
\hline 2007 & $126(11,6)$ & $927(85,0)$ & $7(0,6)$ & $2(0,2)$ & $28(2,6)$ & $1.090(100)$ \\
2008 & $93(9,8)$ & $809(85,7)$ & $6(0,6)$ & $1(0,1)$ & $36(3,8)$ & $945(100)$ \\
2009 & $85(7,8)$ & $954(87,8)$ & $8(0,7)$ & $3(0,3)$ & $37(3,4)$ & $1.087(100)$ \\
2010 & $64(6,3)$ & $900(88,5)$ & $7(0,7)$ & $1(0,1)$ & $45(4,4)$ & $1.017(100)$ \\
2011 & $78(8,2)$ & $818(85,7)$ & $3(0,3)$ & $5(0,5)$ & $51(5,3)$ & $955(100)$ \\
2012 & $79(9,4)$ & $708(84,7)$ & $7(0,8)$ & $2(0,2)$ & $41(4,9)$ & $837(100)$ \\
2013 & $76(9,7)$ & $650(83,0)$ & $3(0,4)$ & $2(0,3)$ & $52(6,6)$ & $783(100)$ \\
\hline Total & $601(9,0)$ & $5766(85,9)$ & $41(0,6)$ & $16(0,2)$ & $290(4,3)$ & $6.714(100)$ \\
\hline
\end{tabular}

Fonte: Elaborada pelos autores com base nos dados do SINAN sujeitos a atualização.

O gênero Crotalus representou entre $0,3 \%$ e $0,8 \%$ das notificações, mostrando valores muito inferiores aos acidentes acarretados por Bothrops. Segundo MORAES et al. (2010, p. 85) "as serpentes do gênero Crotalus apresentam distribuição mais restrita que as do gênero Bothrops, sendo encontradas preferencialmente em campos abertos, áreas secas, arenosas e pedregosas". Outra característica marcante, que consequentemente ajuda a evitar acidentes com estas serpentes, é o seu modo de defesa de levantar e vibrar a cauda com a aproximação de uma pessoa, produzindo um som característico e assim anunciando sua presença (ABEGG \& NETO, 2012; BERNARDE, 2012).

Acidentes com serpentes do gênero Micrurus foram menos frequentes, variando entre $0,1 \%$ e $0,5 \%$, do número total de notificações. Acidentes com este gênero de serpentes são muito raros em todo o Brasil, principalmente devido ao hábito de vida fossorial e abertura bucal que não supera os $30^{\circ}$, além de apresentarem presas muito pequenas de aproximadamente $2,5 \mathrm{~mm}$ em uma serpente coral de 90cm (CARDOSO et al., 2009; ABEGG \& NETO, 2012). Todavia, o envenenamento, quando ocorre, é considerado potencialmente grave pela rápida evolução dos sintomas, que pode levar à insuficiência respiratória aguda, causa de óbito neste tipo de envenenamento (CASAIS et al., 2009).

Incidentes com serpentes não-peçonhentas variaram entre 2,6\% e 6,6\% anualmente do total de notificações. Estes acidentes, geralmente são assintomáticos, no entanto, os gêneros Philodryas, Clelia, Boiruna merecem atenção especial, devido a semelhança do quadro clínico com o envenenamento botrópico (CARDOSO et al., 2009; BERNARDE, 2012).

Registros ignorados ou em branco, correspondentes as ocorrências em que não foi identificado o gênero, foram observados entre 6,3\% e $11,6 \%$ dos casos registrados anualmente. É de extrema importância para uma boa evolução do tratamento do acidentado, que seja identificado o ofídio responsável pelo acidente, em virtude do soro-antiofídico ser específico para cada gênero de serpente (BARROSO \& WOLFF, 2012; ABEGG \& NETO, 2012). A serpente causadora do acidente deve ser transportada para o hospital, sempre que possível com vida, ou uma imagem, até mesmo uma descrição detalhada do ofídio para que a equipe médica saiba qual o melhor tratamento a ser empregado (ABEGG \& NETO, 2012). 
Atitudes como: utilizar botas e luvas em atividades rurais ajudam a prevenir acidentes, já que $80 \%$ das picadas ocorrem na região do joelho para baixo, sendo $50 \%$ dos incidentes no pé (BERNARDE, 2012; BARROSO \& WOLFF, 2012). Para impedir a aproximação de serpentes perto das residências, é recomendável sempre manter limpa áreas do entorno, paióis ou plantações, além de evitar entulhos, montes de lixo e folhas secas dispersas no ambiente (CARDOSO \& SOARES, 2013). Logo, é importante que a temática animais peçonhentos em geral, seja debatida nas escolas, a fim de que os alunos saibam tomar as decisões corretas, em possíveis situações de encontro com estes animais (RAMOS et al., 2012).

\section{CONCLUSÃO}

Ao término do presente estudo, com base nos dados do SINAN, pode-se verificar o perfil epidemiológico dos acidentes ofídicos no Rio Grande do Sul, concluindo dessa forma que grande parte dos indivíduos acometidos pelo ofidismo são homens, predominantemente na faixa etária adulta, evidenciando-se altos índices de cura dos acidentados, porém razoáveis percentuais de casos em que não foi identificado o quadro clínico do paciente, e desta forma, ocultando a verdadeira situação do problema.

Os incidentes ocorreram predominantemente nos meses de outubro a abril, e na maioria os acidentes foram provocados por serpentes do gênero Bothrops. $O$ reconhecimento da situação epidemiológica dos acidentes ofídicos no Estado do Rio Grande do Sul pode propiciar um melhor planejamento por parte dos órgãos da saúde, possibilitando assim a criação de medidas de prevenção mais eficazes ao ofidismo, além de gerar maior capacitação aos profissionais das áreas da saúde.

\section{REFERÊNCIAS}

ABEGG, A.D.; NETO, O.M.E. Serpentes do Rio Grande Do Sul. Tapera; Lew,2012.

BARRETO, B.B.; SANTOS, P.L.C.; MARTINS, F.J.; BARBOSA, N.R.; RIBEIRO, L.C.; LEITE, I.C.G.; VIEIRA, R.C.P.A. Perfil epidemiológico dos acidentes ofídicos no município de Juiz de Fora-MG no período de 2002-2007. Revista Atenção Primária a Saúde, v. 13, n. 2, p. 190-195, 2010.

BARROSO, L.; WOLFF, D. Acidentes causados por animais peçonhentos no Rio Grande do Sul. Engenharia Ambiental: Pesquisa e Tecnologia, v. 9, n. 3, p. 0780862012.

BERNARDE, P.S. Anfíbios e Répteis: introdução ao estudo da herpetofauna brasileira. Curitiba: Anolisbooks, 2012.

BÉRNILS, R. S. E H. C. COSTA (org.). 2014. Répteis brasileiros: Lista de espécies. Sociedade Brasileira de Herpetologia. Disponível em: < http://www.sbherpetologia.org.br/ >.Acessado em 25/08/2015.

BOCHNER, R.; STRUCHINER, C. J. Epidemiologia dos acidentes ofídicos nos últimos 100 anos no Brasil: uma revisão Snake bite epidemiology in the last 100 years in Brazil: a review. Cad. Saúde Pública, v. 19, n. 1, p. 7-16, 2003. 
BRASIL. Ministério da Saúde. Manual de diagnóstico e tratamento de acidentes por animais peçonhentos. $2^{\circ}$ edição; ed. Brasília: Fundação Nacional de Saúde; 2001.

BRASIL. Ministério da Saúde. Sistema de Informação de Agravos de Notificação Sinan Net. Acidente por animais peçonhentos. Disponível em: < http://dtr2004.saude.gov.br/sinanweb/tabnet/dh?sinannet/animaisp/bases/animaisbrn et.def>. Acesso em 04. dez. 2014.

BRITO, A. C.; BARBOSA, I. R. Epidemiologia dos acidentes ofídicos no Estado do Rio Grande do Norte. Con Scientiae Saúde, v. 11, n. 4, p. 535-542, 2012.

CARDOSO, J.L.C., WEN, F.H., FRANÇA, F.O.S., MALAQUE, C.M.S.; HADDAD Jr., V. Animais Peçonhentos no Brasil: biologia, clínica e terapêutica dos acidentes. São Paulo: Sarvier; 2009.

CARDOSO, C.F.L.; SOARES, M.A. Animais Peçonhentos do Município de Mangaratiba, RJ. Revista Eletrônica Novo Enfoque, v. 16, n. 16, p. 25-40, 2013.

CASAIS-E-SILVA, L. L.; BRAZIL, T. K. Acidentes elapídicos no Estado da Bahia: estudo retrospectivo dos aspectos epidemiológicos em uma série de 14 anos (19801993). Gazeta Médica da Bahia, v. 79, n. 1, p. 26-31, 2009.

D'AGOSTINI, F. M.; CHAGAS, F. B.; BELTRAME, V. Epidemiologia dos acidentes por serpentes no município de Concórdia, SC no período de 2007 a 2010. Evidência-Ciência e Biotecnologia, v. 11, n. 1, p. 51-60, 2011.

KASTURIRATNE, A.; WICKREMASINGHE, A. R.; DE SILVA, N.; GUNAWARDENA, N. K.; PATHMESWARAN, A.; PREMARATNA, R; SAVIOLI, L.; LALLOO, D. e DE SILVA, H. J. The Global Burden of Snakebite: A Literature Analysis and Modelling Based on Regional Estimates of Envenoming and Deaths. PLOS Medicine v. 5, p. 1591-1604. 2008.

LEMA, T.D. Os répteis do Rio Grande do Sul: atuais e fósseis, biogeografia, ofidismo. Editora Puc, RS, 2002.

LEMOS, J. C.; ALMEIDA, T. D.; FOOK, S. M.; PAIVA, A. A. e SIMÕES, M. O. S. Epidemiologia dos acidentes ofídicos notificados pelo Centro de Assistência e Informação Toxicológica de Campina Grande (Ceatox-CG), Paraíba. Revista Brasileira de Epidemiologia, v. 12, n. 1, p. 50-59, 2009.

MARTINS, B. F.; CAMPOS, A.P.S.; SELEGHIM, M.R.; BALLANI, T.S.L.; TAVARES, E.O.; OLIVEIRA, M.L.F. Acidentes por serpente (Bothrops spp. e Crotallus spp.) em crianças: relato de dois casos. Revista da Rede de Enfermagem do Nordeste-Rev Rene, v. 13, n. 3, p. 693-703, 2012.

MESCHIAL, W.C.; MARTINS, B.F.; REIS, L.M.; BALLANI, T.S.L.; BARBOZA, C.L. e OLIVEIRA, M.L.F. Internações hospitalares de vítimas de acidentes por animais peçonhentos. Revista da Rede de Enfermagem do Nordeste-Rev Rene, v. 14, n. 2, p. 311-319, 2013. 
MORAES, C. G.; MELO, M. M.; OLIVEIRA, G. H. Aspectos epidemiológicos dos acidentes ofídicos notificados no estado de Goiás, no período entre 2006 e 2008. Revista Educação \& Mudança, n. 23, p. 80-91, 2010.

MOURA, M. R.; COSTA, H.C.; SÃO-PEDRO, V.A.; FERNANDES, V.D.; FEIO, R.N. O relacionamento entre pessoas e serpentes no Leste de Minas Gerais, Sudeste do Brasil. Biota Neotropica, v. 10, n. 4, p. 133-141, 2010.

OLIVEIRA, H. F. A.; COSTA, C. F.; LEITE, R. S. Aspectos Clínico-epidemiológicos dos acidentes com serpentes peçonhentas no município de Cuité, Paraíba, Brasil. Gazeta Médica da Bahia, V.81, p.14-19, 2011.

PINHO, F. M. O.; OLIVEIRA, E. S.; FALEIROS, F. Acidente ofídico no estado de Goiás. Revista da Associação Médica Brasileira, v. 50, n. 1, p. 93-9, 2004.

RAMOS, E. L. P.; MOURA, R.G.F.; MACEDO, M.M.; SIQUEIRA, L.H.C.; SPOSITO, N.E.C.; KATAGUIRI, V.S. Uma abordagem lúdica dos animais peçonhentos no ensino fundamental. Em Extensão, v. 11, n. 2, p. 45-53, 2012.

ROJAS, C. A; SANTOS, S. M. A; GONÇALVES, M. R. Epidemiologia dos acidentes ofídicos na região noroeste do estado de São Paulo, Brasil. Revista Brasileira de Saúde e Produção Animal, v. 8, n. 3,p. 193-204, 2007.

RODRIGUES, C. K. Aspectos clínicos e epidemiológicos dos acidentes por micrurus registrados no Centro de Informações Toxicológicas de Santa Catarina-CIT/SC. Monografia (Trabalho de conclusão de curso)- Curso de Graduação em Medicina, Universidade Federal de Santa Catarina, Florianópolis, 2006.

SCATENA, C. M. C. Vulnerabilidade de pacientes aos acidentes botrópicos no Hospital Vital Brazil do Instituto Butantan-São Paulo. Dissertação de mestradoFaculdade de Medicina da Universidade de São Paulo, São Paulo, 2013. 